\title{
Combined vertebral fracture assessment and bone mineral density measurement: a new standard in the diagnosis of osteoporosis in academic populations
}

\author{
P. L. Jager • S. Jonkman • W. Koolhaas • A. Stiekema • \\ B. H. R. Wolffenbuttel • R. H. J. A. Slart
}

Received: 5 March 2010 /Accepted: 23 April 2010 /Published online: 23 June 2010

(C) The Author(s) 2010. This article is published with open access at Springerlink.com

\begin{abstract}
Summary Vertebral Fracture Analysis enables the detection of vertebral fractures in the same session as bone mineral density testing. Using this method in 2,424 patients, we found unknown vertebral fractures in approximately one out of each six patients with significant impact on management.
\end{abstract}

The current report is the final and main paper of the project 'Improving Osteoporosis Diagnostics', in Dutch « Verbeterde Osteoporose

Diagnostiek, or VOD study. A preliminary report on the first 1000 patients in this study appeared in the Dutch Medical Journal in the Dutch language. Koolhaas W, Prak A, Stiekema HM, Kreeftenberg HG, Wolffenbuttel BH, Jager PL. [Efficient and improved diagnosis of osteoporosis by simultaneous bone density measurement and spinal morphometry]. Ned Tijdschr Geneeskd. 2008 Apr 19;152(16):938-43. Jager PL, Slart RH, Webber CL, Adachi JD, Papaioannou AL, Gulenchyn KY. Combined Vertebral Fracture Assessment and Bone Mineral Density Measurement: A Patient-Friendly New Tool with an Important Impact on the Canadian Risk Fracture Classification. Can Assoc Radiol J. 10.1016/j.carj.2009.12.012. A substudy of this main study dealing with detailed comparison of radiographs and VFA in a subgroup has appeared in Radiology. Hospers IC, van der Laan JG, Zeebregts CJ, Nieboer P, Wolffenbuttel BHR, Dierckx RA, Kreeftenberg H, Jager PL, Slart RHJA. Vertebral fracture assessment in supine position: comparison with semiquantitative and visual radiograph assessment. Radiology. 2009;251:822-828.

\section{P. L. Jager}

Department of Nuclear Medicine, Isala Clinics,

Dr. van Heesweg 2,

8000 BM Zwolle, The Netherlands

\section{P. L. Jager $(\bowtie)$}

Department of Nuclear Medicine,

Hamilton Health Sciences/McMaster University,

Hamilton, ON, Canada

e-mail: p.1.jager@isala.nl

\section{S. Jonkman · A. Stiekema • R. H. J. A. Slart}

Department of Nuclear Medicine and Molecular Imaging,

University Medical Center, Groningen, University of Groningen,

Groningen, The Netherlands
Introduction The presence of osteoporotic vertebral fractures (VF) is an important risk factor for all future fractures independent of BMD. Yet, determination of the VF status has not become standard practice. Vertebral Fracture Assessment (VFA) is a new feature available on modern densitometers. In this study we aimed to determine the prevalence of VF using VFA in all patients referred for BMD testing in a university medical center and to evaluate its added clinical value.

Methods Prospective diagnostic evaluation study in 2,500 consecutive patients referred for BMD. Patients underwent VFA in supine position after BMD testing. Questionnaires were used to assess perceived added value of VFA.

Results In 2,424 patients (1,573 women), results were evaluable. In 541 patients (22\%), VFA detected a prevalent VF that was unknown in $69 \%$. In women, the prevalence was $20 \%$ versus $27 \%$ found in men $(p<0.0001)$. The prevalence of VF was $14 \%$ in patients with normal BMD (97/678), increased to $21 \%(229 / 1,100)$ in osteopenia and to $26 \%$ in those with osteoporosis $(215 / 646)$ by WHO

W. Koolhaas

Department of Health Sciences,

University of Groningen,

Groningen, The Netherlands

B. H. R. Wolffenbuttel

Department of Endocrinology,

University of Groningen,

Groningen, The Netherlands 
criteria. After excluding mild fractures VF prevalence was $13 \%(322 / 2,424)$. In 468 of 942 questionnaires $(50 \%$ response rate), $27 \%$ of the referring physicians reported VFA results to impact on patient management.

Conclusions VFA is a patient friendly new tool with a high diagnostic yield, as it detected unknown VF in one out of each six patients, with significant impact on management. We believe these findings justify considering VFA in all new patients referred for osteoporosis assessment in similar populations.

Keywords Bone mineral density measurement. Osteoporosis · Vertebral fracture assessment .

Vertebral fractures

\section{Introduction}

The vertebral fracture status is a powerful and independent risk factor for all new fractures, which is a major health care problem in the aging population of the western world [1-3]. Most patients with vertebral fractures are not clinically recognized. Although the concept of risk factors is gaining ground, the current clinical practice of osteoporosis assessment is still largely based on bone mineral density (BMD) measurement only [4]. Additional imaging studies of the spine have not become routine for a multitude of reasons, including lack of awareness of the vertebral fracture status as independent risk factor and possibly because osteoporosis is a condition secondary to many other diseases and it is not the "core" expertise of many physicians. In addition, considerable underreporting of vertebral fractures on plain X-rays and even on $\mathrm{CT}$ at rates of up to $50 \%$ has been demonstrated in many countries worldwide [5, 6]. For that reason it is now advised to specifically use the word "fracture" in reports. Furthermore costs, radiation issues, patient inconvenience and other reasons preclude more widespread recognition of vertebral fracture status as important to assess. This likely leads to undertreatment, as many patients with vertebral fractures do not have BMD T-scores in the osteoporotic range and would not be selected for pharmacological therapy based on BMD scores alone $[7,8]$.

In recent years new developments in BMD equipment allow assessment of vertebral fracture status using the same machine as used for the BMD measurement. The bone densitometer acquires a radiographic image of nearly the entire spine immediately after BMD measurement. In this way, two major risk factors, BMD and vertebral fracture status, are assessed in a single, short session. This procedure is now called Vertebral Fracture Assessment (VFA), although in the past terms as "Vertebral Morphometry," "Instant Vertebral Assessment," "Absorptiometry" and other terms have been used. Image quality of VFA now approaches that of a standard radiograph. Its radiation dose is less than $1 \%$ of a comparable radiograph, and is considered extremely low at 3 microSievert, which is in the same order as 1 day of normal life [9]. In a substudy of this project, we validated the reliability of our VFA interpretation against radiographs and similar to many other reports we found an excellent agreement and good accuracy of VFA [10]. Some controversy exists regarding the detection of mild vertebral fractures in the upper thoracic spine, and VFA might be slightly less reliable there [11]. On the other hand, interpretation and image quality of radiographs is also difficult in this area and vertebral fractures are rare in the upper thoracic spine.

In this academic population, we prospectively studied VFA, which was applied routinely in all patients referred for BDM measurement, to assess the rate of vertebral fracture and used questionnaires to study the impact on management.

\section{Patients and methods}

\section{Patients}

We prospectively included all consecutive patients of 18 years or older who were referred for BMD measurement to the department of Nuclear Medicine of the University Medical Center Groningen, in the northeast of The Netherlands. Inclusion started in November of 2005 and ended in October 2007.

These patients came from many different departments and outpatient clinics, including internal medicine, endocrinology, immunology, rheumatology, and gynecology and also included many patients referred by a recently started "osteoporosis and fracture clinic," where every patient over 50 years with a low-energy fracture is assessed for osteoporosis. In general our population harbors a relatively high frequency of patients with suspected secondary osteoporosis, and also contains patients with lung-, liver-, and kidney transplantation patients, various autoimmune, endocrine diseases, inflammatory bowel disease, etc.

The study was approved by the Institutional Ethics Review Board and all patients gave informed consent. From the patients and from hospital records we recorded demographic information, some risk factors and data on the disease or condition that had led to the referral for BMD measurement. Both DXA and VFA were acquired using a Hologic Discovery A densitometer (Hologic Inc., Bedford, MA, USA).

To obtain an impression on the perceived added value of VFA and its impact on management a short questionnaire was sent to the referring physician together with the integrated $\mathrm{BMD} / \mathrm{VFA}$ results (based on in the first 1,000 patients. Questions included whether a spine X-ray 
had been requested with the original BMD requisition, whether the physician would have requested a spine Xray after receiving the BMD report, whether the VFA information added to the BMD report improved their understanding of the patient's osteoporosis status, and whether and how BMD and VFA data each influenced planned management.

\section{BMD measurement}

BMD was measured using standard methods over the lumbar spine L1-L4, the total proximal femur and the $1 / 3$ distal radius, and results were expressed as T-scores. The standard Hologic reference databases for Caucasian men and women were used. The reference standard of a T-score is the peak bone density, as reached in men or women between 20-30 years of age. The T-score is then defined as the number of standard deviations from this score. According to the commonly used WHO definition, "osteoporosis" is defined as a T-score lower than -2.5 , "osteopenia" as a Tscore between -2.5 and -1.0 , and when the T-score is greater than $-1.0 \mathrm{BMD}$ is "normal." $\mathrm{BDM}$ equipment underwent daily Qc and regular maintenance, however, local precision values were not available.

\section{Vertebral Fracture Assessment}

Immediately after BMD measurements VFA was performed. While the patient remained in a supine position the $\mathrm{C}$-arm of the machine moved to the lateral position and then a lateral fan-beam X-ray image of the spine was obtained. The maximum range of vertebral visualization is from the level of T4 through L4. Three experienced technologists analyzed all images under supervision of experienced nuclear medicine specialists and radiologists. These technologists had all been trained both for nuclear medicine and radiology procedures, and had over 5 years of work experience and underwent additional training in vertebral fracture recognition. Careful note was taken in patients with scoliosis or degenerative disease, and when vertebrae could not be interpreted they were excluded. In case of other vertebral abnormalities, additional radiographs were suggested. In agreement with the instructions of the manufacturer, dedicated software was used to place six markers on cranial and caudal aspects of vertebral bodies in anterior, posterior and in the middle position. The technologists corrected marker placement manually in $\sim 80 \%$ of the patients, usually in the upper thoracic spine only. Reproducibility was measured in the first 100 patients. The difference between the detection of a vertebral fracture among the three technologists was $3 \%$ on a per patient basis. Differences were resolved by consensus and all final placements and final reports were checked by nuclear medicine physicians and radiologists at the time of reporting. The Hologic software then determined the anterior, posterior and middle vertebral body heights from the marker points and calculated the degree and type of vertebral shape anomalies, using the Genant classification, which is now considered the most appropriate method [12]. In this classification a relative height reduction (with reference to posterior-mid-anterior heights) between $20-25 \%$ was designated a "mild" fracture, $25-40 \%$ a "moderate" fracture, and $>40 \%$ as a "severe" fracture [13-15]. Type of vertebral fracture could be "wedge" when the anterior height was the lowest, "biconcave" when middle height was the lowest or "crush" when posterior height was the lowest.

The original Genant classification, however, prescribes visual inspection and only measurements of those vertebrae that appear visually abnormal. However, we felt that this approach leads to even more variability and unreliability as intra- and interobserver variability of visual radiological interpretation is considerable. Therefore, we chose to meticulously measure each vertebra with a visual quality check in all cases.

\section{Statistical analysis}

We decided to include 2,500 patients, which approximately amounts to a study duration of 2 years supported by our funding. We assumed that the precision of our main outcome parameter, the prevalence of vertebral fractures, would be sufficient with this sample size, and that approximately 2,500 patients would generate subgroups based on sex, BMD class, age group, affected vertebral level of sufficient size to allow reasonable precision of the prevalence estimates within such subgroups. Basically this study uses descriptive statistics only. The subgroup comparisons were based on Student's $t$ tests with $p$ values of 0.05 as cutoff values. Univariate analysis was performed, but we refrained from multivariate analysis as predictive factors for vertebral fractures are sufficiently known and not the aim of this study. Statistical evaluations were performed using SPSS version 15 and Microsoft Excel software.

\section{Results}

\section{Patients}

After the target inclusion of 2,500 patients was reached, the study was stopped and the data were analyzed. Most patients were referred because of suspected secondary osteoporosis. Approximately two thirds of the group came for a first BMD measurement; in the remaining patients this was a follow-up test. Nearly one quarter of the patients had a recent low-energy fracture. More patient data are presented in Table 1. 
Table 1 Patient characteristics

\begin{tabular}{|c|c|c|c|c|}
\hline & Number & SD & Range & Percent \\
\hline Total included & 2,424 & & & \\
\hline \multicolumn{5}{|l|}{ Sex } \\
\hline Male & 851 & & & 35 \\
\hline Female & 1,573 & & & 65 \\
\hline Postmenopausal women & 1,240 & & & 51 \\
\hline Mean age (years) & 53 & 15 & $18-94$ & \\
\hline Males (years) & 50 & 15 & $18-87$ & \\
\hline Females (years) & 54 & 15 & $18-94$ & \\
\hline Mean weight (kg) & 74 & 15 & $33-150$ & \\
\hline \multicolumn{5}{|l|}{ Referring specialties } \\
\hline Orthopedics/Traumatology & 613 & & & 25 \\
\hline Endocrinology & 336 & & & 14 \\
\hline Systemic Diseases & 288 & & & 12 \\
\hline General Intern. Med. & 254 & & & 11 \\
\hline Gynaecology & 284 & & & 12 \\
\hline Other & 615 & & & 25 \\
\hline Family physicians & 34 & & & 1 \\
\hline Indication & 662 & & & 27 \\
\hline Primary osteoporosis & 1,762 & & & 73 \\
\hline Secondary osteoporosis & 1,641 & & & 68 \\
\hline First visit & 783 & & & 32 \\
\hline \multicolumn{5}{|l|}{ Follow-up visit } \\
\hline Steroid use & 1,705 & None & & 70 \\
\hline On $<7,5 \mathrm{mg} /$ day & 151 & & & 6 \\
\hline On $>7,5 \mathrm{mg} /$ day & 568 & & & 24 \\
\hline Ever & 960 & & & 40 \\
\hline Never & 1,464 & & & 60 \\
\hline Known with vertebral fracture & 185 & & & 8 \\
\hline Recent low-energy fracture & 570 & & & 24 \\
\hline
\end{tabular}

Vertebral Fracture Assessment quality

In $76(3 \%)$ patients, results of VFA were technically inadequate and the results were considered unreliable. This was caused by severe scoliosis $(n=17)$, inability to lay supine because of clinical condition $(n=23)$, severe adiposity $(n=5)$, and miscellaneous reasons $(n=31)$. In the remaining 2,424 patients, VFA was considered reliable. Image quality was subjectively scored as "good" in 2097 (87\%), "moderate" in $294(12 \%)$, and "poor" in 33 patients (1\%), and was based on assessment of the whole image. Despite "poor" or "moderate" VFA image quality results in those patients were considered sufficiently reliable to allow analysis.

The levels that were adequately visualized by VFA were from vertebra L4 up through vertebra T4 in 1,991 (82\%) patients, from L4 through T5 in 2,247 (93\%), and from L4 through T6 in 2,402 (99\%). In total, around 30,000 vertebral bodies were analyzed.
Vertebral Fracture Assessment results

VFA demonstrated a vertebral fracture in 541 (22\%) of the patients. An example is presented in Fig. 1. These 541 patients together had 954 vertebral fractures, which amounts to a mean of 1.8 fractures per patient with a fracture. In 375 patients $(69 \%$ of those with a fracture, or $16 \%$ of the whole cohort), these fractures were not demonstrated earlier and were unknown according to the patient.

The distribution of the fractures over the individual vertebral levels showed the well-known dual-peak distribution with a peak at T7 (119 fractures, 13\% of total) and at T12 (169 fractures, $18 \%$ of total) (Fig. 2). The severity of the fractures was "mild" in 458 (48\% of all fractures), "moderate" in 295 (31\%), and "severe" in 201 (21\%). Vertebral fractures were wedge shaped in $79 \%(n=759)$, biconcave in $19 \%(n=178)$ and "crush" in $2 \%(n=17)$. Mild fractures were often accompanied by moderate or severe 
Fig. 1 Example of a VFA study result with left the image after placing marker points, upper right the Genant classification and lower a table with the percentages of deformity. In this patient, one moderate vertebral fracture was detected: wedge shaped in L1

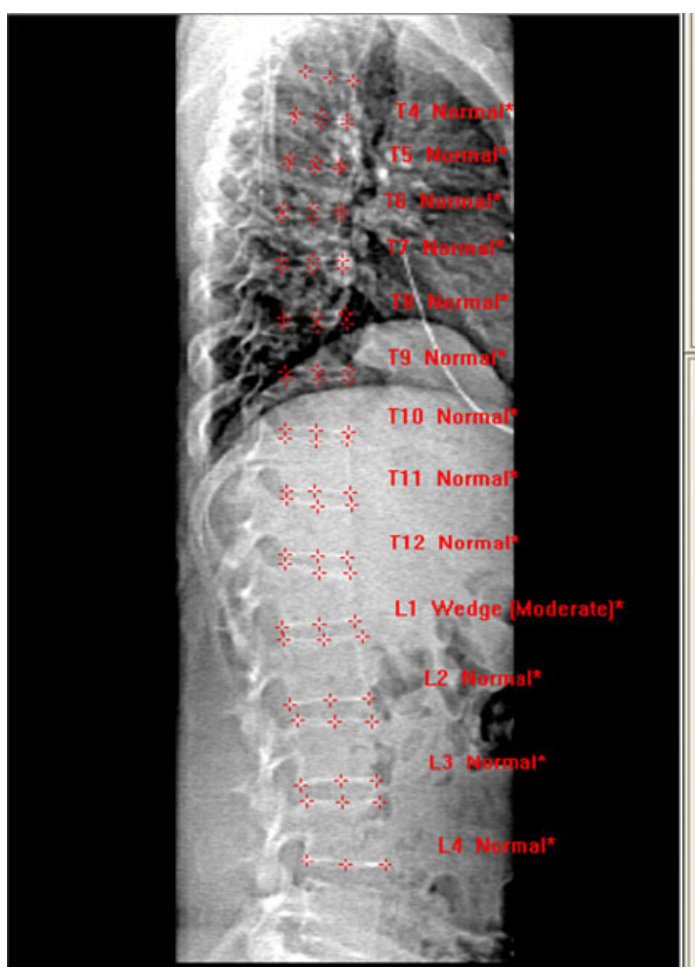

fractures, and on a per patient analysis 219 patients $(9 \%$ of all patients) had mild fractures only.

As there has been controversy in the definition of mild fractures we also analyzed the data for moderate and severe fractures only, after excluding mild fractures. The prevalence of moderate or severe vertebral fractures was $322(13 \%)$ in this cohort, $180(56 \%)$ were unknown. The distribution followed the same dual-peak pattern as for all fractures.

Factors influencing the prevalence of vertebral fractures are reported in Table 2. Regarding sex distribution, the prevalence of vertebral fractures was higher in men than in women, and also the percentage in which such fractures were unknown was higher in men $(75 \%$ in men and $65 \%$ in women). Limiting these data to moderate and severe fractures only, the prevalence in men was $15 \%(131 / 851)$ and $12 \%$ in women $(191 / 1,573)$.

The age distribution of vertebral fractures is presented in Table 3. As expected the prevalence of vertebral fractures increases with age and reached approximately $50 \%$ in patients older than 70 years. Of interest, the proportion of moderate and severe fractures also increased with age. Further stratifying this for sex the rate of vertebral fractures
Fig. 2 Frequency distribution of vertebral fractures assessed with VFA

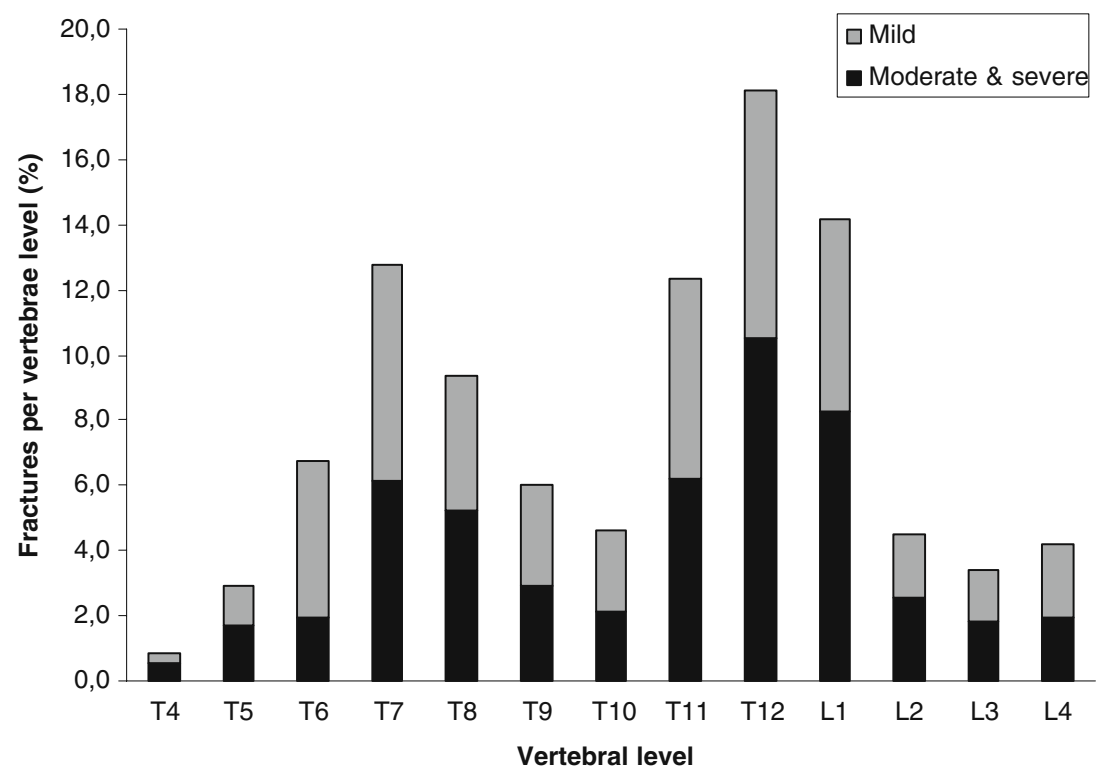


Table 2 Univariate analysis of variables influencing vertebral fracture status

\begin{tabular}{|c|c|c|c|c|c|}
\hline Factor & Number & $\%$ of total & Number with VF & Percent & $p(t$ test $)$ \\
\hline Sex & & & & & $<0.0001$ \\
\hline Male & 851 & $35.1 \%$ & 232 & $27 \%$ & \\
\hline Female & 1573 & $64.9 \%$ & 309 & $20 \%$ & \\
\hline Female menopausal status & & & & & $<0.0001$ \\
\hline Pre & 332 & $21.2 \%$ & 22 & $7 \%$ & \\
\hline Post & 1241 & $78.8 \%$ & 287 & $23 \%$ & \\
\hline Visit status & & & & & 0.31 \\
\hline First & 1641 & $67.7 \%$ & 376 & $23 \%$ & \\
\hline Follow-up & 783 & $32.3 \%$ & 165 & $21 \%$ & \\
\hline Osteoporosis suspicion & & & & & $<0.0001$ \\
\hline Primary & 662 & $27.3 \%$ & 221 & $33 \%$ & \\
\hline Secondary & 1762 & $72.7 \%$ & 320 & $18 \%$ & \\
\hline Recent low-energy fracture & & & & & $<0.0001$ \\
\hline Yes & 570 & $23.5 \%$ & 190 & $33 \%$ & \\
\hline No & 1854 & $76.5 \%$ & 351 & $19 \%$ & \\
\hline Steroid use (ever) & & & & & 0.006 \\
\hline Yes & 960 & $39.6 \%$ & 187 & $20 \%$ & \\
\hline No & 1464 & $60.1 \%$ & 354 & $25 \%$ & \\
\hline Smoker & & & & & 0.76 \\
\hline Yes & 593 & $24.5 \%$ & 135 & $23 \%$ & \\
\hline No & 1831 & $75.5 \%$ & 406 & $22 \%$ & \\
\hline Ever previous fracture & & & & & $<0.0001$ \\
\hline Yes & 1251 & $52 \%$ & 346 & $28 \%$ & \\
\hline No & 1173 & $48 \%$ & 195 & $17 \%$ & \\
\hline $\mathrm{X}$-spine in last 2 years & & & & & $<0.0001$ \\
\hline Yes & 838 & $35 \%$ & 276 & $33 \%$ & \\
\hline No & 1586 & $65 \%$ & 265 & $17 \%$ & \\
\hline Self-reported posture change & & & & & $<0.0001$ \\
\hline Yes & 400 & $17 \%$ & 174 & $44 \%$ & \\
\hline No & 2024 & $83 \%$ & 367 & $18 \%$ & \\
\hline $\mathrm{X}$-spine requested with BMD request & & & & & $<0.0001$ \\
\hline Yes & 190 & $41 \%$ & 66 & $35 \%$ & \\
\hline No & 276 & $59 \%$ & 54 & $20 \%$ & \\
\hline
\end{tabular}

Table 3 Age distribution and prevalence of vertebral fractures (VF)

\begin{tabular}{|c|c|c|c|c|c|}
\hline Age group & $N$ in age group & $N$ with VF & $\%$ with VF & $\%$ with mild VF only & $\%$ with moderate or severe $\mathrm{VF}$ \\
\hline $11-20$ & 38 & 2 & 5.3 & 5.3 & 0 \\
\hline $21-30$ & 191 & 14 & 7.3 & 5.2 & 2.1 \\
\hline $31-40$ & 275 & 31 & 11.2 & 5.8 & 5.4 \\
\hline $41-50$ & 386 & 58 & 15.0 & 8.5 & 6.5 \\
\hline $51-60$ & 728 & 155 & 21.3 & 9.5 & 11.8 \\
\hline $61-70$ & 508 & 139 & 27.4 & 10.4 & 17.0 \\
\hline $71-80$ & 216 & 103 & 47.7 & 13.0 & 34.7 \\
\hline $81-90$ & 81 & 39 & 48.1 & 11.1 & 37.0 \\
\hline$>90$ & 1 & 0 & - & - & - \\
\hline Total & 2424 & 541 & 22.1 & 8.9 & 13.3 \\
\hline
\end{tabular}


in men was $10 \%, 19 \%, 21 \%, 28 \%, 36 \%, 49 \%, 50 \%$ in the age groups of Table 3, versus 5\%,7\%, 11\%, 18\%, 22\%, $47 \%, 49 \%$ in women.

Other factors that were associated with higher prevalence of vertebral fractures were postmenopausal status of women as compared to premenopausal status, primary osteoporosis vs. secondary osteoporosis, recent lowenergy fracture, use of steroids, history of any fracture, patients who underwent spinal radiograph in the last 2 years and self-reported posture change. No difference was found in vertebral fracture prevalence in those who came for a first vs. follow-up visit and in smokers vs. non-smokers.

Regarding previous X-rays, 838 (35\%) of the patients had undergone a spine radiograph in the last 2 years before the BMD assessment. In 276 (33\%) of these patients, we found one or more vertebral fractures. In 156 of these patients $(54 \%$ of those who had a radiograph), this fracture - 81 of which were moderate or severe-was unknown to the patient, indicating that either the fracture had occurred after the previous X-ray examination or the X-ray results had not been communicated to the patient. In the 138 patients known to have a vertebral fracture based on previous X-rays, VFA confirmed this in 129 (93\%). An extensive sub study focused on detailed comparison of VFA with radiographs in a subgroup has been published elsewhere [10].

\section{BMD and VFA results}

As expected, a relationship was found between the BMD and the prevalence of vertebral fractures (Table 4). In the entire cohort $28 \%$ of the patients had a normal BMD. In this subgroup a vertebral fracture was still found using VFA in $14 \%(97 / 678)$ that was unknown in $74 \%$. Osteopenia was found in $45 \%$ of the cohort, and in $21 \%$ $(229 / 1,100)$ of that subgroup a vertebral fracture was detected, that was unknown in $71 \%$. Osteoporosis was diagnosed in $27 \%$ of the cohort. In 33\% (215/646) of these patients, a vertebral fracture was found, that was unknown in $65 \%$.

The frequency of patient with at least one severe fracture was $9 \%(12 / 135)$ in those with normal BMD, rose to $36 \%$ $(48 / 135)$ in those with osteopenia and to $56 \%(75 / 135)$ in those with osteoporosis, indicating that not only the frequency but also the severity of the fractures increased with decreasing BMD.

Impact of VFA

In the first 1,000 patients we aimed to send a questionnaire to the requesting physicians to obtain their initial and obviously subjective opinion of the BMD and VFA findings. In 58 patients, VFA results were technically inadequate and therefore 942 questionnaires were sent out. Of these, 468 were received back (50\% response rate). Results are reported in Table 5.

In total, $271(58 \%)$ physicians reported that VFA had improved their understanding of the patients' osteoporosis status. In this group $35 \%$ of the patients had a vertebral fracture. One hundred twenty-nine responders $(27 \%)$ reported an impact of VFA on their medical management, and in that group $45 \%$ had a vertebral fracture. Therefore, apparently also the absence of vertebral fractures (in the other 55\%) still influenced treatment.

To get an impression on "questionnaire return bias," the prevalence of vertebral fracture in patients whose physicians did not return the questionnaire was $21 \%$, whereas in the others the prevalence was $26 \%(p<0.001)$. It could be argued that the findings of a vertebral fracture would favor returning the questionnaire and the opinion of positive understanding and impact on treatment. Therefore the $27 \%$ of requesting physicians reporting positive impact of VFA may have been an overestimation. However, the general unfamiliarity of the VFA technique and the subjectivity of questionnaires in general should lead to cautious interpretation of these results.

\section{Discussion}

The aim of this study was to determine the value of VFA added to BMD measurement in consecutive patients scheduled for BMD assessment in an academic center. This constitutes a rather specific "academic"population that also included a large fraction (24\%) with a recent low-energy fracture. The results show that addition of VFA enabled the detection of one or more vertebral fractures in $22 \%$ of this population, and in $69 \%$ of these patients the fracture was
Table 4 Bone mineral density classification and the prevalence of vertebral fractures (VF)

\begin{tabular}{lllll}
\hline BMD class & $\begin{array}{l}\mathrm{N} \\
(\% \text { total })\end{array}$ & $\begin{array}{l}\text { N with VF } \\
(\% \text { class })\end{array}$ & $\begin{array}{l}\text { N with only mild VF } \\
(\% \text { VF) }\end{array}$ & $\begin{array}{l}\text { VF unknown } \\
(\% \text { BMD class })\end{array}$ \\
\hline Normal & $678(28 \%)$ & $97(14 \%)$ & $46(47 \%)$ & 74 \\
Osteopenia & $1,100(45 \%)$ & $229(21 \%)$ & $104(45 \%)$ & 71 \\
Osteoporosis & $646(27 \%)$ & $215(33 \%)$ & $69(32 \%)$ & 65 \\
\hline
\end{tabular}


Table 5 Results of the physician questionnaires on the impact of VFA $(\mathrm{n}=468)$

\begin{tabular}{|c|c|c|}
\hline & Number & Percent \\
\hline \multicolumn{3}{|c|}{$\mathrm{X}$-ray requested with $\mathrm{BMD}$ requisition } \\
\hline Yes & 190 & 40 \\
\hline No & 276 & 59 \\
\hline Unknown & 2 & 1 \\
\hline \multicolumn{3}{|c|}{$\mathrm{X}$-ray requested after receiving BMD report } \\
\hline Yes & 41 & 9 \\
\hline No & 410 & 88 \\
\hline Unknown & 17 & 3 \\
\hline \multicolumn{3}{|c|}{ Impact of VFA on understanding patient osteoporosis status } \\
\hline No impact & 178 & 38 \\
\hline Some impact & 225 & 48 \\
\hline Large impact & 46 & 10 \\
\hline Unknown & 19 & 4 \\
\hline \multicolumn{3}{|c|}{ Impact of BMD findings on management } \\
\hline Yes & 350 & 75 \\
\hline No & 114 & 24 \\
\hline Unknown & 4 & 1 \\
\hline \multicolumn{3}{|c|}{ Impact of VFA findings on management } \\
\hline No impact & 323 & 69 \\
\hline Some impact & 100 & 21 \\
\hline Large impact & 29 & 6 \\
\hline Unknown & 16 & 3 \\
\hline \multicolumn{3}{|l|}{ Type of impact } \\
\hline Change in medication & 51 & 39 \\
\hline Different lifestyle advise & 35 & 27 \\
\hline Other & 37 & 29 \\
\hline Medication plus lifestyle & 7 & 5 \\
\hline
\end{tabular}

unknown. Even when mild fractures would have been omitted, the method still detected vertebral fractures in 13\% of this population, $56 \%$ of which were unknown. In other words in approximately one out of each six patients an unknown vertebral fracture was found, and in one out of each 14 patients an unknown moderate or severe vertebral fracture was detected. This can be considered a high diagnostic yield.

The detection of a vertebral fracture often leads to medical treatment in patients that would otherwise not have been treated. In our study we detected unknown vertebral fractures in nearly one out of each 6 patients. It has been demonstrated in many studies that treatment reduces future fracture risk for prolonged periods, and this might lead to decreased hospitalizations [16-19]. Formal costs of VFA are not established in many countries, but most likely will be lower than the BMD assessment itself, and most likely be cheaper than radiographs of the thoracic and lumbar spine. In the papers by
Olenginski et al. and Lewiecki et al., a cost of $\$ 30-40$ is quoted $[11,20]$. The high diagnostic yield and positive impact on treatment at relatively low costs suggests favorable cost-effectiveness of this test, but this evidently requires more study. For the more expensive spine radiographs, there is a report suggesting cost-effective use in postmenopausal women $>60$ years with a T-score of lesse than -1.5 and treatment of those women with prevalent vertebral fractures [21]. For VFA, there is currently one report indeed suggesting cost-effective application in osteopenic postmenopausal women [22]. Addition of VFA to BMD therefore appears to give a valuable contribution to the management of osteoporosis.

In this study, we attempted to get an initial opinion of the value of VFA in an actual clinical setting, by means of sending questionnaires to the referring physicians. As many physicians are reluctant to fill out questionnaires, and they are subjective by nature, the results should be interpreted with caution. However, $58 \%$ of the physicians reported that VFA improved their understanding of their patient's osteoporosis status, and $27 \%$ reported an impact on their management. These results seem to confirm the perceived added value and the relatively high diagnostic yield of the VFA technique.

Multiple studies including our own sub study of the current report have now demonstrated good agreement between both methods with very good sensitivities and specificities using radiographs as a gold standard, and even more so for the moderate and severe fractures $[10,13,23-27]$. The slightly decreased reliability for assessment of mild fractures of the upper thoracic levels does not seem to preclude the added value of VFA, as vertebral fractures are considerably less common in that range, which was also evident in our study. In addition, one could wonder whether standard spinal radiographs are suitable as a true reference standard to compare VFA with. Also radiographs have difficulty visualizing the upper thoracic levels, quality varies considerably and over projection of skeletal and lung structures often decrease readability in that area. Because the X-ray beam is divergent and focused on T7 lower and higher vertebrae contain variable degrees of magnification and distortion, while VFA images all vertebras in an orthogonal direction without parallax. Moreover, many previous VFA/radiograph comparative studies have used VFA with the patient in a lateral rather than supine position, which may be less optimal but that has not been demonstrated. In our sub study VFA even provided the lowest number of uninterpretable vertebrae [10]. One advantage of radiographs is that the intensity of the X-ray beam can be better suited to the body habitus of the patient, rather than the standard settings of the VFA. And as VFA is designed for osteoporotic fracture assessment specifically, other causes of deformity such as Scheuermann's 
disease, congenital malformations, malignant, inflammatory or degenerative disease can be much better recognized on radiographs. A large drawback for everyday clinical practice is the fact that performing measurements of vertebrae can be very time consuming in a busy radiology practice. Taken together, all these factors support the use of VFA.

The prevalence rate detected in this study is in general agreement with other reports although the epidemiology of vertebral fractures is less well documented as compared to hip fractures. In European population-based studies prevalence figures in the order of $13 \%, 20 \%$, and $30 \%$ are found in age groups $50-59,60-69$, and $70-79$, respectively $[28,29]$. Our corresponding figures of $22 \%, 28 \%$, and $49 \%$ are significantly higher, probably as a result of the characteristics of our population. Prevalence in Europe appears to be relatively high compared to other places in the world $[28,29]$.

Our results seem to confirm again that the vertebral fractures status is largely independent of the bone density. This is illustrated by our finding that even in patients with normal bone density a vertebral fracture was found in $14 \%$ (Table 4). This percentage rose to $21 \%$ in patients with osteopenia and to $33 \%$ in patients with osteoporosis. Our findings and interpretations are also in agreement with the conclusions of the comprehensive review on VFA by Lewiecki et al. [11].

This study was performed in an "academic" Dutch population, where many patients were assessed for secondary osteoporosis with a wide variety of medical conditions. It is not a population-based study. However, in this cohort we found a lower rate of vertebral fractures among patients studied because of secondary osteoporosis as compared to primary osteoporosis. The latter group contained however many patients referred from the fracture clinics. Although not the primary aim of this study, the results also confirm the well-known variables associated with higher vertebral fracture risk, such as age, BMD, postmenopausal status in women, history of fractures, use of steroids, self-reported posture change (Table 2, 3).

In 2008 the International Society of Clinical Densitometry published a position statement on the application of VFA [12]. Appropriate indications were very complex, and include postmenopausal women with osteopenia and additionally combinations of age group, historical height loss $>4 \mathrm{~cm}$, prospective height loss of $>2 \mathrm{~cm}$, self-reported prior vertebral fracture, chronic systemic disease associated with increased risk of vertebral fracture. For men similar complex indications are described including only men with osteopenia and combinations of age group, height loss levels, self-reported vertebral fracture, androgen deprivation therapy and chronic diseases. In addition, all women on glucocorticoid therapy and all persons with osteoporosis by BMD criteria in whom vertebral fractures would alter management were considered indications for VFA. The general purpose of all these variables is to select a subgroup with a higher a priori likelihood of finding a vertebral fracture to improve cost-effectiveness. However, the cost of VFA is low and the prevalence of vertebral fractures is already $>10 \%$ in patients over 30 years of age and rises rapidly with advancing age (Table 3 ). This suggests that there is no real need to select subgroups to raise the diagnostic yield. In addition, it could be argued that in patients with osteoporosis by BMD criteria alone treatment should be initiated and VFA will not change this. However, the presence of vertebral fractures even in such patients significantly increases the risk profile, which would seem worthwhile to know. We therefore propose to consider VFA in all patients referred for a first BMD test. In daily clinical practice requests for VFA with BMD in new patients are already frequently observed.

In conclusion, VFA combined with bone mineral density assessment is a simple, patient friendly procedure that provides important additional information in a large proportion of patients at low cost. The method detects previously unknown vertebral fractures in nearly one out of each six patients. In similar populations, we therefore suggest that this method should be considered in every new patient that is referred for BMD assessment.

Funding This study was partly sponsored by the Innovation Foundation of the University Medical Center Groningen, The Netherlands (grant 179.320/JA). A grant of 145,000 Euros was provided to finance 70,000 Euros as part of the purchase of the Hologic Discovery A densitometer which was a replacement for an older version, and to provide with 2 years of 0.5 FTE nuclear medicine technologist (75,000 Euros) to perform and process the studies and to manage the data.

Conflicts of interest None.

Open Access This article is distributed under the terms of the Creative Commons Attribution Noncommercial License which permits any noncommercial use, distribution, and reproduction in any medium, provided the original author(s) and source are credited.

\section{References}

1. Delmas PD, Genant HK, Crans GG, Stock JL, Wong M, Siris E, Adachi JD (2003) Severity of prevalent vertebral fractures and the risk of subsequent vertebral and nonvertebral fractures: results from the MORE trial. Bone 33:522-532

2. Lindsay R, Silverman SL, Cooper C, Hanley DA, Barton I, Broy SB, Licata A, Benhamou L, Geusens P, Flowers K, Stracke H, Seeman E (2001) Risk of new vertebral fracture in the year following a fracture. JAMA 285:320-323

3. Melton LJ III, Atkinson EJ, Cooper C, O'Fallon WM, Riggs BL (1999) Vertebral fractures predict subsequent fractures. Osteoporos Int 10:214-221 
4. Kanis JA, Johnell O, Oden A, Johansson H, McCloskey E (2008) FRAX and the assessment of fracture probability in men and women from the UK. Osteoporos Int 19:385-397

5. Bartalena T, Giannelli G, Rinaldi MF, Rimondi E, Rinaldi G, Sverzellati N, Gavelli G (2007) Prevalence of thoracolumbar vertebral fractures on multidetector $\mathrm{CT}$ : underreporting by radiologists. Eur J Radiol 69(3):555-559

6. Kim N, Rowe BH, Raymond G, Jen H, Colman I, Jackson SA, Siminoski KG, Chahal AM, Folk D, Majumdar SR (2004) Underreporting of vertebral fractures on routine chest radiography. AJR Am J Roentgenol 182:297-300

7. Schuit SC, van der Klift M, Weel AE, de Laet CE, Burger H, Seeman E, Hofman A, Uitterlinden AG, van Leeuwen JP, Pols HA (2004) Fracture incidence and association with bone mineral density in elderly men and women: the Rotterdam Study. Bone 34:195-202

8. Wainwright SA, Marshall LM, Ensrud KE, Cauley JA, Black DM, Hillier TA, Hochberg MC, Vogt MT, Orwoll ES (2005) Hip fracture in women without osteoporosis. J Clin Endocrinol Metab 90:2787-2793

9. Vokes T, Bachman D, Baim S, Binkley N, Broy S, Ferrar L, Lewiecki EM, Richmond B, Schousboe J (2006) Vertebral fracture assessment: the 2005 ISCD Official Positions. J Clin Densitom 9:37-46

10. Hospers IC, van der Laan JG, Zeebregts CJ, Nieboer P, Wolffenbuttel BH, Dierckx RA, Kreeftenberg HG, Jager PL, Slart RH (2009) Vertebral fracture assessment in supine position: comparison by using conventional semiquantitative radiography and visual radiography. Radiology 251:822-828

11. Lewiecki EM, Laster AJ (2006) Clinical review: clinical applications of vertebral fracture assessment by dual-energy X-ray absorptiometry. J Clin Endocrinol Metab 91:4215-4222

12. Schousboe JT, Vokes T, Broy SB, Ferrar L, McKiernan F, Roux C, Binkley N (2008) Vertebral fracture assessment: the 2007 ISCD Official Positions. J Clin Densitom 11:92-108

13. Binkley N, Krueger D, Gangnon R, Genant HK, Drezner MK (2005) Lateral vertebral assessment: a valuable technique to detect clinically significant vertebral fractures. Osteoporos Int 16:15131518

14. Genant HK, Wu CY, Van KC, Nevitt MC (1993) Vertebral fracture assessment using a semiquantitative technique. J Bone Miner Res 8:1137-1148

15. McCloskey EV, Spector TD, Eyres KS, Fern ED, O'Rourke N, Vasikaran S, Kanis JA (1993) The assessment of vertebral deformity: a method for use in population studies and clinical trials. Osteoporos Int 3:138-147

16. Black DM, Schwartz AV, Ensrud KE, Cauley JA, Levis S, Quandt SA, Satterfield S, Wallace RB, Bauer DC, Palermo L, Wehren LE, Lombardi A, Santora AC, Cummings SR (2006) Effects of continuing or stopping alendronate after 5 years of treatment: the Fracture Intervention Trial Long-term Extension (FLEX): a randomized trial. JAMA 296:2927-2938
17. Quandt SA, Thompson DE, Schneider DL, Nevitt MC, Black DM (2005) Effect of alendronate on vertebral fracture risk in women with bone mineral density $\mathrm{T}$ scores of -1.6 to -2.5 at the femoral neck: the Fracture Intervention Trial. Mayo Clin Proc 80:343-349

18. Wells GA, Cranney A, Peterson J, Boucher M, Shea B, Robinson V, Coyle D, Tugwell P. Etidronate for the primary and secondary prevention of osteoporotic fractures in postmenopausal women. Cochrane Database Syst Rev 2008; CD003376

19. Wells GA, Cranney A, Peterson J, Boucher M, Shea B, Robinson $\mathrm{V}$, Coyle D, Tugwell P. Alendronate for the primary and secondary prevention of osteoporotic fractures in postmenopausal women. Cochrane Database Syst Rev 2008; CD001155

20. Olenginski TP, Newman ED, Hummel JL, Hummer M (2006) Development and evaluation of a vertebral fracture assessment program using IVA and its integration with mobile DXA. J Clin Densitom 9:72-77

21. Schousboe JT, Ensrud KE, Nyman JA, Kane RL, Melton LJ III (2005) Potential cost-effective use of spine radiographs to detect vertebral deformity and select osteopenic post-menopausal women for amino-bisphosphonate therapy. Osteoporos Int 16:1883-1893

22. Schousboe JT, Ensrud KE, Nyman JA, Kane RL, Melton LJ III (2006) Cost-effectiveness of vertebral fracture assessment to detect prevalent vertebral deformity and select postmenopausal women with a femoral neck T-score $>-2.5$ for alendronate therapy: a modeling study. J Clin Densitom 9:133-143

23. Chapurlat RD, Duboeuf F, Marion-Audibert HO, Kalpakcioglu B, Mitlak BH, Delmas PD (2006) Effectiveness of instant vertebral assessment to detect prevalent vertebral fracture. Osteoporos Int 17:1189-1195

24. Pavlov L, Gamble GD, Reid IR (2005) Comparison of dualenergy X-ray absorptiometry and conventional radiography for the detection of vertebral fractures. J Clin Densitom 8:379-385

25. Rea JA, Chen MB, Li J, Marsh E, Fan B, Blake GM, Steiger P, Smith IG, Genant HK, Fogelman I (2001) Vertebral morphometry: a comparison of long-term precision of morphometric X-ray absorptiometry and morphometric radiography in normal and osteoporotic subjects. Osteoporos Int 12:158-166

26. Schousboe JT, DeBold CR (2006) Reliability and accuracy of vertebral fracture assessment with densitometry compared to radiography in clinical practice. Osteoporos Int 17:281-289

27. Steiger P, Cummings SR, Genant HK, Weiss H (1994) Morphometric $\mathrm{X}$-ray absorptiometry of the spine: correlation in vivo with morphometric radiography. Study of osteoporotic fractures research group. Osteoporos Int 4:238-244

28. Cummings SR, Melton LJ (2002) Epidemiology and outcomes of osteoporotic fractures. Lancet 359:1761-1767

29. O'Neill TW, Felsenberg D, Varlow J, Cooper C, Kanis JA, Silman AJ (1996) The prevalence of vertebral deformity in european men and women: the European Vertebral Osteoporosis Study. J Bone Miner Res 11:1010-1018 